Original Article

\title{
Source of Bleeding and Per-Operative Findings in Extradural Hematoma (EDH): A Three-Year Experience in a Teaching Institute
}

\author{
Sohail Amir ${ }^{1}$, Riaz-ur-Rehman ${ }^{2}$, Shahid Ayub ${ }^{1}$, Muhammad Ali Numan ${ }^{1}$ \\ Department of Neurosurgery, ${ }^{1}$ Hayatabad Medical Complex, ${ }^{2}$ Leady Reading Hospital/MTI, Peshawar, \\ Pakistan
}

\begin{abstract}
Objective: The objective of this study was to analyze the main source of bleeding and operative findings in an extradural hematoma (EDH).

Material and Methods: A descriptive study was conducted at the Neurosurgery Department of Hayatabad Medical Complex Peshawar from March 2017 to April 2020.The study included 550 patients that met the criteria of inclusion well. Demographic profile, location of Extra-Dural hematoma, the source of bleeding, presence or absence of skull fracture and per operative findings were documented in structured proforma.
\end{abstract}

Results: $69 \%$ were male and $31 \%$ were female patients. The middle age group of $21-40$ years mostly affected. Rupture or laceration of middle meningeal artery was the communal source of bleeding in 355 (64.5\%) patients, followed by fracture bone in 285 (51.8\%) of patients and dural venous sinus in 70 (12.7\%) of patients. Preoperative findings in our study were linear skull fracture in 250 (45.4.0\%), underlying contusion in 165 (30\%), and contralateral hematoma in $70(12.7 \%)$ of cases.

Conclusion: Rupture or laceration of a Middle meningeal artery (MMA) was the most communal source of bleeding in extradural hematoma. Therefore, per-operative cauterization of this vessel is important to prevent the chances of re-bleed and re-do surgeries.

Keywords: Extradural Hematoma (EDH), Source of Bleeding, Middle Meningeal Artery.

\section{Corresponding Author: Sohail Amir \\ Department of Neurosurgery \\ Hayatabad Medical Complex \\ Peshawar \\ Email: dr.sohailamir@gmail.com}

Date of Submission: 24-01-2021

Date of Revision: 13-02-2021

Date of Online Publishing: 31-03-2021

Date of Print: 31-03-2021

DOI: $10.36552 /$ pjns.v25i1.505

\section{INTRODUCTION}

Head injury is the most communal cause of death in young adults. Injury to the head result in decreased level of consciousness, memory disturbance and neurodeficits. ${ }^{1,2}$ Traumatic brain injury is a serious problem which needs to be treated and the incidence is very high almost 20 per 1,00,000 people per year. ${ }^{3}$ Extradural hematoma $(E D H)$ is bleeding between the skull and outermost layer of the brain, which is called 
dura. $^{4}$ It usually occurs in the temporoparietal region in almost $70-80 \%$ cases and may extend to adjacent occipital or frontal area. However, $\mathrm{EDH}$ in the posterior fossa is less common and accounts only for 0.3 percent of all intracranial hematomas. ${ }^{5,6}$ The most common etiology of EDH is road accident, fall, direct blow to the head, physical Assault, firearm and sports related injuries. ${ }^{7}$ Among these, direct blow to the head is often associated with skull fractures. ${ }^{8}$

The EDH should be suspected in any patient with significant head trauma. Patient may present with focal sign like, decrease movement on one side of body, dilated pupil, or fits and may have non focal sign like decreased level of consciousness, headache and vomiting. However, the classical presentation is head injury leading to brief loss of consciousness followed by lucid interval and further mental deterioration. ${ }^{9,10}$

The vascular source of extradural hematoma is due to rupture or laceration of middle meningeal artery and its branches in the area of temporal bone. It may also occur due to diploic veins and dural venous sinuses. ${ }^{11}$ Direct blow to the skull will lead to the formation of hematoma on the same side while in rare cases it can be found on opposite side due to counter coup injury. ${ }^{12,13} \mathrm{EDH}$ may also be associated with underlying contusion, subarachnoid hemorrhage, subdural hematoma, intracerebral bleed, pneumocephalus and sometimes laceration of dura. ${ }^{14}$

Surgery is a mainstay of treatment for EDH having volume more than $30 \mathrm{ml}$ on the CT-Scan brain. Surgical removal of a part of the skull bone to expose the brain is performed to evacuate the hematoma, ${ }^{15}$ a procedure called craniotomy. Delay in surgery may result in serious consequences and outcome. Mortality rate depends upon multiple factors and the most significant is the patient's presenting GCS. The mortality rate in patients with GCS between 13 15 is less than $5 \%$, while those having GCS less than 13 have a $10-20 \%$ poorer outcome. ${ }^{16}$ The current study was aimed to find out the main source of bleeding and per-operative findings in $\mathrm{EDH}$.

\section{MATERIAL AND METHODS}

\section{Study Design \& Setting}

A descriptive study was conducted at the Neurosurgery Department of Hayatabad Medical Complex Peshawar, from March 2017 to April 2020. A prior approval for the study was taken from the hospital ethical and research committee. Patients were informed about the procedure and proceeded after their consent.

\section{Inclusion Criteria}

All those patients included who were operated for extradural hematoma (EDH) irrespective of age and gender.

\section{Exclusion Criteria}

However, those patients having bleeding problems or using anti-coagulants drugs were exempted from the study.

\section{Data Collection}

Detailed history including sex, age of the patients, presenting GCS, CT scan findings, operative findings, size $\&$ site of hematoma, presence or absence of skull fracture were documented on a proforma. The source of bleeding was noted from the operative notes, which was either from a middle meningeal artery, fracture site, diploic vein, dural venous sinus or generalized ooze from the dura. The data was analyzed using SPSS version 23.0 . 


\section{RESULTS}

\section{Study Subjects}

A total of 550 subjects were included for 3 years. 380 (69\%) were male patients and 170 (30.9\%) were females. Male to female ratio was 2:1. Among these patients, the most common age group was 21 - 30 years (Table 1), where 176 (32\%) cases had a history of falls, followed by age group of 31 - 40 years which included 101 (18.3\%) patients. Mean age was $30.4 \pm 3.22$ years.

Table 1: Distribution of patients according to age group $(n=550)$.

\begin{tabular}{|ccc|} 
Age Group in Years & Number of Patients & Percentage \\
$0-10$ & 51 & $9.27 \%$ \\
$11-20$ & 75 & $13.63 \%$ \\
$21-30$ & 176 & $32 \%$ \\
$31-40$ & 101 & $18.3 \%$ \\
$41-50$ & 73 & $13.2 \%$ \\
$51-60$ & 48 & $8.720 \%$ \\
Above 60 & 26 & $4.72 \%$ \\
\hline
\end{tabular}

\section{Location of Bleeding}

The commonest location of $\mathrm{EDH}$ was Temporoparietal area 216 (39.2\%) followed by frontal 148 (26.9\%) and parietal area in 101 (18.36\%) of patients as shown in Table 2. In our study, 285 (51.8\%) of patients at presentation had a mild head injury with a GCS between $13-15$. Those with moderate head injury and GCS $(9-12)$ were 180 (32.8\%) and severe head injury with GCS $(3-8)$ in $85(15.9 \%)$ of patients.

Table 2: Location of Hematoma $(n=550)$.

\begin{tabular}{lcc|} 
Location & Number of Patients & Percentage \\
Temporo parietal & 216 & $39.27 \%$ \\
Frontal & 148 & $26.9 \%$ \\
parietal & 101 & $18.36 \%$ \\
Occipital & 75 & $13.63 \%$ \\
Posterior fossa & 10 & $1.8 \%$ \\
\hline
\end{tabular}

\section{Sources of Hematoma and Bleeding}

Temporo parietal (40\%) was the most common location of the hematoma among the patients (Table 2). The most common source of bleeding was middle meningeal artery in 355 (64.5\%) patients, fracture bone in 285 (51.8\%) of patients, and injury to dural venous sinus in $70(12.7 \%)$ of patients. The generalized ooze was found in 48 (8.72\%) patients. In 15 (2.72\%) patients, we could not identify the source of bleeding (Table 3 ).

Table 3: Source of Bleeding $(n=550)$.

\begin{tabular}{lcc} 
Source of Bleeding & $\begin{array}{c}\text { Number of } \\
\text { Patients }\end{array}$ & Percentage \\
Middle meningeal artery & 355 & $64.5 \%$ \\
Fracture bone & 285 & $51.8 \%$ \\
Venous sinuses & 70 & $12.7 \%$ \\
Generalized ooze & 48 & $8.72 \%$ \\
Not identified & 15 & $2.72 \%$ \\
\hline
\end{tabular}

\section{Operative Findings}

The craniotomy/craniectomy was done to evacuate the hematoma. Preoperative findings in our study were linear skull fracture in 250 (45.4\%), underlying contusion in 165 (30\%) and contra lateral hematoma in 70 (12.7\%) patients. Associated subdural hematoma was seen in 50 (9.0\%) and dural laceration in only 15 (2.7\%) of cases (Table 4 ).

Table 4: Operative findings $(n=550)$.

$\begin{array}{lcc}\text { Operative Findings } & \begin{array}{c}\text { Number of } \\ \text { Patients }\end{array} & \text { Percentage } \\ \text { Skull fracture } & 250 & 45.4 \% \\ \text { Contralateral hematoma } & 70 & 12.7 \% \\ \text { Underlying contusion } & 165 & 30 \% \\ \text { Associated subdural } & 50 & 9.0 \% \\ \text { hematoma } & 15 & 2.7 \% \\ \text { Dural laceration } & \end{array}$

\section{DISCUSSION}

Head injury is a globally serious issue. It is either primary or secondary. The primary injury is a direct mechanical blow to the head while, 
secondary injury occurs as a cascade of primary injury which may include cerebral edema, altered cerebral blood flow impaired metabolism, and formation of toxins. A primary insult to the brain occurs at the site of event and difficult to prevent, while secondary insult to the brain can be prevented by managing the patients following trauma protocols meticulously. ${ }^{17}$ Morbidity and mortality due to severe head injury are very high, but over the past few decades due to advancement in knowledge, skills and investigating tools it decreases.

In this study, the commonest age group of 21 - 30 years was documented. People do physical work in this age group and have more exposure to surrounding and therefore more prone to road traffic accident, fall and physical violence. Due to more exposure to the environment and society the males in the community are more prone to head trauma and hence EDH. Similar data was produced by Naveed and Rehman in Pakistan. ${ }^{18,19}$ We identified that the temporo parietal as a hematoma location was the most common. Moreover, a middle meningeal artery was the most common source of bleeding. In our study, a skull fracture was identified in the majority of the patients. The location of EDH is of paramount value as it is one of the predictors of prognosis. It is best described on the CT Scan Brain. Supra tentorial EDH is more common than infratentorial hematoma. Some studies also show that the frontal EDH was more common. ${ }^{19}$ The study done by Azam and Ali depicted that the sole cause of bleeding in EDH is fracture of the bone in $75 \%$ followed by the middle meningeal artery which differs with our study. ${ }^{20}$ Craniotomy, and where necessary, a wide craniectomy is done to remove the clot. In our study, we see per operatively, a linear skull fracture in 250 (45.40\%), underlying contusion in 165 (30\%), contralateral hematoma in 70 (12.7\%). Associated subdural hematoma was seen in 50 (9.0\%) and dural laceration in only 15 (2.7\%) of cases. Similar findings were depicted by Babu and
Kumar showing associated injuries like bilateral hematoma in $9 \%$ and underlying contusion in $39 \%$ of cases. ${ }^{21}$ Association of linear skull fracture with EDH in different studies varies from 30 $50 \%^{15}$.

\section{CONCLUSION}

Rupture or laceration of the middle meningeal artery is the most communal source of bleeding in extradural hematoma. Therefore, per-operative cauterization of this vessel is important to prevent the chances of re-bleed and re-do surgeries. In addition, bleeding from the fracture site also contributes to form hematoma and has to be taken into consideration. Vigilant examination/ investigation, quick diagnosis and prompt action to do surgery will give better result.

\section{REFERENCES}

1. Reballi R, Kasimanhanti SP. Neurophysciatric complication of traumatic brain injury and orthopedic injury: a comparative study. APJ Psychol Med. 2014; 15 (2): 228-34.

2. Moppet K. Traumatic brain injury: assessment, resuscitation and early management. $\mathrm{Br} J$ Anesth. 2007; 99 (1): 18-31.

3. Husson EC, Ribbers GM, Willmse-van Son $A H$, Verhagen AP, Stam HJ. Prognosis of six month functioning after moderate to severe traumatic brain injury: A systemic review of prospective cohort studies. J Rehabil Med. 2010; 42: 425-36.

4. Agarwal A, Agarwal CS, Kumar A, Adhikari S. Outcome of experience of 300 cases. Nigerian J Ortho Trauma. 2007; 6 (2): 74-6.

5. Mahmood M, Elgheriany A, Mousa AE et al. Traumatic posterior fossa extradural hematoma. Reporting of an additional 8 cases. Egy Neur Surg. 2011; 26 (2): 83-92.

6. Labato RD, Alen JF, Pervez-Nunez A, Alday R, Gomez PA, Pascual B, et al. Value of CT scanning and intracranial pressure monitoring for detecting new intracranial mass effect in severe head injury patients showing lesion type-I-II in the initial CT 
scan. Neurociurgia. 2005; 16: 217-34.

7. Greenwald RM, Gwin GT, Chu JJ, Crisco JJ. Head impact severity measures for evaluating mild traumatic brain injury risk. Exposure Neurosurg. 2008; 62 (4): 789-98.

8. Uzkan U, Kemalogulu S, Ozates M, Guzel A, That M. Analyzing extradural hematoma: A retrospective clinical investigation. Dicle Tip Dergisi. 2007; 34 (1): 14-19.

9. Rehman R, Mushtaq M, Haq MI, Azam F, Khattak A. Skull fracture on $x$-ray skull as indicator of extradural hematoma in patient with head injury. Pak J Surg. 2012; 28 (2): 106-9.

10. Ibanez J, Arikan F, Pedraza $S$ et al. reliability of clinical guidelines in the detection of patients at risk following mild head injury: result of prospective study. J Neurosurg. 2004; 100 (5): 82534.

11. Kumar A, Lalwani S, Agarwal D, Rautji R, Dogra TD. Fatal road traffic accident and their relationship with head injuries: An epidemiological survey of five years. Indian J Neurot. 2008; 5 (2): 63-7.

12. Khan IU, Nadeem M. There is high incidence of skull fracture associated with extradural hematoma in patients with head injury. Rawal Med J. 2008; 33: 228-30.

13. Khan MJ, Shaukat A, Khalid M, Aziz MA. Surgical Management and outcome analysis of extradural hematoma at combined military Hospital Rawalpindi. Pak Arm Force Med J. 2009; 59 (1):
70-3.

14. Sunay YM, Mahmut A, Gurcel C, Yasemin GB, Muzaffer $A$. The correlation between skull fractures and intracranial lesions due to traffic accidents. Am J Foren Med Pathol. 2003; 24 (4): 339-45.

15. Babu ML, Bhasin SK, Kumar A. Extradural hematoma-An experience of 300 cases. JK Science, 2005; 7 (4): 205-7.

16. Bullock MR, Chesnut R, Ghajar J, Gordon D, Hartl R, Newell DW, Servadei F, Walter BC, Wilberger JE. Surgical management of acute epidural hematoma. Neurosurg. 2008; 58 (3): 2-7.

17. Servadei F, Ciucci G, Pagano F, Rebucci GG, Ariano $M$, Piazza $G$, Giast $G$. Skull fracture as a risk factor of intracranial complications in minor head injuries: a prospective CT study in a series of adult patients. J Neurol Neurosurg Psychiat. 1988; 32 (1): 526-8.

18. Naveed D, Bhatti SN, Akbar M, Aurangzeb A. Etiology, presentation and outcome of head injury patients admitted in Ayub teaching hospital Abbottabad. Kust Med J. 2010; 2 (2): 45-8.

19. Rehman L, Khattak A, Naseer A, Mushtaq. Outcome of acute traumatic extradural hematoma. J Coll Physicians Surg Pak. 2008; 18 (12): 759-62.

20. Azam F, Ali M, Khan B, Hussain R, Alam I, Khan M, Khan BZ. Source of bleeding in acute extra-dural hematoma. Pak J of Neurol. Surg. 2013; 17 (1): 4446.

\section{Additional Information}

Disclosures: Authors report no conflict of interest.

Ethical Review Board Approval: The study was conformed to the ethical review board requirements.

Human Subjects: Consent was obtained by all patients/participants in this study.

\section{Conflicts of Interest:}

In compliance with the ICMJE uniform disclosure form, all authors declare the following:

Financial Relationships: All authors have declared that they have no financial relationships at present or within the previous three years with any organizations that might have an interest in the submitted work.

Other Relationships: All authors have declared that there are no other relationships or activities that could appear to have influenced the submitted work. 


\section{AUTHORS CONTRIBUTIONS}

\begin{tabular}{|l|l|l|}
\hline Sr.\# & Author's Full Name & Intellectual Contribution to Paper in Terms of: \\
\hline 1. & Sohail Amir & Study design and methodology. \\
\hline 2. & Riaz-ur-Rehman & Paper writing, referencing and data calculations. \\
\hline 3. & Shahid Ayub & Data collection and calculations \\
\hline 4. & Muhammad Ali Numan & Analysis of data and interpretation of results etc. \\
\hline
\end{tabular}

